\title{
A Note on Fuzzy Upper and Lower Weakly Semi - Precontinuous Multifunction
}

\author{
Saurabh Saxena \\ Hitkarini College of Engineering \& Technology Jabalpur (M.P.), India
}

\begin{abstract}
This paper is devoted to the introduction and study of fuzzy lower and upper weakly semi-precontinuous multifunction between a general topological space $(X, \tau)$ and a fuzzy topological space $(y, \sigma)$ using the lower inverse $f$ and upper $f^{\dagger}$ several equivalent conditions of a lower and upper weakly Semi-precontinuous multifunctions are obtained.
\end{abstract}

Keywords: Fuzzy Continuity, Fuzzy Semicontinuous, Fuzzy semipre-continuous, Fuzzy multifunctions

\section{Introduction}

Through the paper by $(\mathrm{x}, \tau)$ or simply by $\mathrm{X}$ we will mean a topological space in a classical sense and $(y, \sigma)$ or simply by $\mathrm{Y}$ will stand for a fuzzy topological space (fts, for short) as defined by chang [2], Fuzzy sets in to $\mathrm{Y}$ will be denoted $\lambda$, $\mu, \vartheta \&$ etc. And interior and closure fuzzy sets $\lambda$ in an fts $Y$ will be denoted by int $\lambda$ and $\operatorname{cl}(\lambda)$ and respectively a fuzzy set $\lambda$ of fts $\mathrm{Y}$ is called fuzzy $\alpha$ - open set (fuzzy $\alpha$ - closed) if $\mathrm{A} \leq$ int $\operatorname{cl}(\lambda)$ ). Then $\alpha$ - closure and $\alpha$-interior of $\lambda$ are defined as follows:

$\alpha c c_{-}=\mathrm{D}\{\mu / \mu$ is fuzzy $\alpha$ closed and $1 \leq \mu\}$

When a fuzzy set 1 is quasi-coincident (q-coincident,for short) with a fuzzy set $\lambda$ in $(y, \sigma)$ we shell write lq, $m$ if $\lambda$ and $\mu$ are not quasi-coincident denoted by $(\lambda q \mu)$. The words 'neighbourhood ' and fuzzy topological space 'will be abbreviated as 'nbd' and 'fts' respectively.

\section{On Fuzzy Weakly Semi-precontinuous Multifunctions}

Definition (1.1.1) Let $(X, \tau)$ be a topological space in the classical sens and $(y, \sigma)$ be a fuzzy topological space $f: x ! y$ is called fuzzy multifunction for each $\mathrm{x} 2 \mathrm{X}$., $\mathrm{f}(\mathrm{x})$ is a fuzzy set in $\mathrm{y}$.

Definition (1.1.2) For a fuzzy multifunction $f: x \rightarrow y$ the $\mathrm{f}(\mathrm{A})$ of fuzzy set $\mathrm{A}$ in $\mathrm{Y}$ are defined as follows:

$\mathrm{f}(\mathrm{A})=\mathrm{f}(\mathrm{x}) \varepsilon \mathrm{X}: \mathrm{F}(\mathrm{x}) \mathrm{qA}$,

$\mathrm{f}(\mathrm{A})=\mathrm{f}(\mathrm{x}) \varepsilon \mathrm{X}: \mathrm{F}(\mathrm{x}) \leq \mathrm{A}$

Theorem (1.1.1) For a fuzzy multifunction $f: x \rightarrow y$ we have $f(1-A)=x-f(A)$ for any fuzzy set $A$ in $Y$.

Definition (1.13) For a fuzzy multifunction $f: x \rightarrow y$ is called:

(a) Fuzzy lower and precontinuous at a point $x_{0} \varepsilon X$ if for every fuzzy open set $\mathrm{V}$ in $\mathrm{Y}$ will $\mathrm{x}_{0} \varepsilon \mathrm{F}^{-}(\mathrm{V})$, there exist a semi preopen nbd $\mathrm{U}$ of $\mathrm{x}_{0}$ in $\mathrm{X}$ such that $\mathrm{U} \dot{\mathrm{C}} \mathrm{F}(\mathrm{v})$.

(b) Fuzzy upper and precontinuous at a point $\mathrm{x}_{0} \varepsilon \mathrm{X}$ if for every fuzzy open set $\mathrm{V}$ in $\mathrm{Y}$ will $\mathrm{x}_{0} \varepsilon \mathrm{F}^{+}(\mathrm{V})$, there exist a semi preopen nbd $U$ of $x_{0}$ in $X$ such that $U F(v)$.

(c) Fuzzy lower semii- precontinuous on $\mathrm{X}$ iff it is respectively so that each $\mathrm{x}_{0} \& \mathrm{X}$. (d) Fuzzy semi-pre continuous on X,iff it is fuzzy lower semi-precontinuous and fuzzy upper semi precontinuous mapping.

Definition (1.14) For a fuzzy multifunction $\mathrm{f}: \mathrm{x} \rightarrow \mathrm{y}$ is called :

(a) Fuzzy lower weakly semi-continuous at a point $x_{0} \varepsilon X$. Iff for every fuzzy open set $\mathrm{V}$ in $\mathrm{Y}$ will $\mathrm{x}_{0} \varepsilon f(\mathrm{v})$, there exists a semi open nbd $U$ of $x_{0}$ in $X$ such that $U \varepsilon$ $\mathrm{f}_{0}$ (SCIV).

(b) Fuzzy lower weakly semi-continuous at a point $\mathrm{x}_{0} \varepsilon \mathrm{X}$ iff for every fuzzy open set $\mathrm{V}$ in $\mathrm{Y}$ will $\mathrm{x}_{0} \varepsilon \mathrm{f}(\mathrm{v})$, there exists a semi open nbd $U$ of $x_{0}$ in $X$ such that $U \varepsilon$ fO(SCIV).

(c) Fuzzy lower weakly semi-continuous on $\mathrm{X}$ iff it is respectively so each $\mathrm{x}_{0} \varepsilon \mathrm{X}$.

(d) Fuzzy weakly semi- continuous on $X$ iff it is fuzzy lower weakly semi-continuous and fuzzy upper weakly semi-continuous mapping.

\section{Lower and Upper Weakly Semi- Precontinuous Fuzzy Multifunctions}

Definition (2.1) For a fuzzy multifunction $\mathrm{f}: \mathrm{x} \rightarrow \mathrm{y}$ is called :

(a) Fuzzy lower weakly semi-precontinuous at a point $\mathrm{x} 0 \varepsilon$ $\mathrm{X}$ iff for every fuzzy open set $\mathrm{V}$ in $\mathrm{Y}$ will $\mathrm{x}_{0} \varepsilon$ . $F(v)$. There exist a semi preopen nbd of $U$ of $x_{0}$ in $X$ such that Uं்F(SCLV).

(b) Fuzzy lower weakly semi-precontinuous at a point $\mathrm{x}_{0} \varepsilon$ $\mathrm{X}$ iff for every fuzzy open set $\mathrm{V}$ in $\mathrm{Y}$ will $\mathrm{x}_{0} \varepsilon \mathrm{F}(\mathrm{v})$. There exist a semi preopen nbd of $U$ of $x_{0}$ in $X$ such that UCंF(SCLV).

(c) Fuzzy lower weakly semi-precontinuous on $\mathrm{X}$ iff it is respectively so at each $\mathrm{x}_{0} \varepsilon \mathrm{X}$.

(d) Fuzzy weakly semi-precontinuous on $\mathrm{X}$ iff it is fuzzy lower weakly semi-precontinuous and fuzzy upper weakly semi-precontinuous mapping.

Theorem (2.3) Let $\mathrm{f}: \mathrm{x} \rightarrow \mathrm{y}$ is fuzzy lower weakly semiprecontinuous iff every fuzzy open set $\mathrm{V}$ in $\mathrm{F}(\mathrm{V})$ _SP int F(SCIV) (respectively,F(v) Cं SPint F(SCIV). 


\section{International Journal of Science and Research (IJSR) \\ ISSN (Online): 2319-7064 \\ Index Copernicus Value (2013): 6.14 | Impact Factor (2015): 6.391}

Theorem (2.4) If $\mathrm{f}: \mathrm{x} \rightarrow \mathrm{y}$ is lower weakly semiprecontinuous, for every fuzzy pre- semiopen set $\mathrm{V}$ in $\mathrm{F}(\mathrm{v})$ C SPint F(SCIV)

Theorem (2.5) Iff : $\mathrm{x} \rightarrow \mathrm{y}$ is fuzzy upper weakly semiprecontinuous for every fuzzy pre-semiopen set $\mathrm{V}$ in $\mathrm{Y}$, F(V) C SPint F(SCIV)

Theorem(2.6) If $\mathrm{f}: \mathrm{x} \rightarrow \mathrm{y}$ is fuzzy lower weakly semiprecontinuous on $\mathrm{X}$, Then SPCL $\mathrm{f}(\mathrm{V}) \dot{\mathrm{C}} \mathrm{F}(\mathrm{SCLV})$ for any fuzzy open set V in $\mathrm{Y}$.

Theorem (2.7) If $\mathrm{f:} x \rightarrow \mathrm{y}$ is fuzzy upper weakly semiprecontinuous on $\mathrm{X}$, Then SPCL $\mathrm{f}(\mathrm{V}) \dot{\mathrm{C}} \mathrm{F}(\mathrm{SCLV})$ for any fuzzy open set $\mathrm{V}$ in $\mathrm{Y}$.

Theorem (2.8) Let $\mathrm{f}: \mathrm{x} \rightarrow \mathrm{y}$ is fuzzy multifunction then following are equivalent :

(a) $\mathrm{F}$ is lower weakly semi-precontinuous.

(b) For any fuzzy open set $\mathrm{V}$ in $\mathrm{Y}, \mathrm{F}(\mathrm{V}) \dot{\mathrm{C}} \mathrm{SP}$ int $\mathrm{F}(\mathrm{SCLV})$ int $\mathrm{F}(\mathrm{SCLV})$ and $\mathrm{F}(\mathrm{V}) \dot{\mathrm{C}} \mathrm{F}(\mathrm{SCLV})$.

Theorem (2.9) Let $\mathrm{f}: \mathrm{x} \rightarrow \mathrm{y}$ is fuzzy lower weakly semiprecontinuous if for each fuzzy open V,F(SCLV) is fuzzy semi pre-open set.

Definition(2.2) For a fuzzy multifunctiom $\mathrm{f}: \mathrm{x} \rightarrow \mathrm{y}$ the $\mathrm{F}$ (A) and $\mathrm{F}^{+}(\mathrm{A})$ of a fuzzy set

$\lambda$ in $Y$ are defined as follows:

$\mathrm{F}^{-}(\lambda)=\mathrm{f}(\mathrm{x}) \varepsilon \mathrm{X}: \mathrm{F}(\mathrm{x}) \mathrm{q} \lambda$

$F^{+}(\lambda)=f(x) \varepsilon X: F(x) \lambda$

Definition (2.3) A fuzzy multifunction $f:(x, \tau) \rightarrow(y, \sigma)$ is said to be :

(a) Fuzzy upper continuous at a point $\mathrm{x}$ of $\mathrm{X}$ for any fuzzy open set $\lambda$ of $\mathrm{Y}$ such that $\mathrm{F}(\mathrm{x}) \leq \lambda$ there exist $\mathrm{u} \varepsilon \tau$ containing $x$ such that $F(u) \leq \lambda$ for all $u \varepsilon U$.

(b) Fuzzy upper continuous at a point $\mathrm{x}$ of $\mathrm{X}$ for any fuzzy open set $\lambda$ of $Y$ such that $F(x) q \lambda$, there exist $u \varepsilon \tau$ containing $x$ such that $F(u) q \lambda$ for all $u \in U$.

(c) For upper (resp.fuzzy lower) continuous if it is fuzzy upper (resp.lower) continuous at every point of X.

Definition (2.4): A fuzzy multifunction $\mathrm{f}: \mathrm{x} \rightarrow \mathrm{y}$ is called:

(a) A fuzzy lower weakly $\alpha$-continuous at a point $x \varepsilon X$ if for every fuzzy open set $\lambda$ in $\mathrm{Y}$ with $\mathrm{x} \varepsilon \mathrm{X}$ such that $\mathrm{F}^{-}$ $(\lambda)$. There exist a nbd $\mathrm{u}$ of $\mathrm{x}_{0}$ in $\mathrm{X}$ such that $\mathrm{U} \dot{\mathrm{C}} \mathrm{F}^{-}((\mathrm{Cl}(\lambda)$

(b) A fuzzy upper weakly $\alpha$-continuous at a point $\mathrm{X} \varepsilon \mathrm{X}$ if for every fuzzy open set $\lambda$ in $\mathrm{Y}$ with $\mathrm{x} \varepsilon \mathrm{X}$ such that $\mathrm{F}+(\lambda)$. There exist a nbd $\mathrm{u}$ of $\mathrm{x}_{0}$ in $\mathrm{X}$ such that $\mathrm{U} \dot{\mathrm{C}} \mathrm{F}+$ $((\mathrm{Cl}(\lambda))$

\section{Lower and Upper Weakly a-Continuous Fuzzy Multifunctions}

Definition (3.1): For a fuzzy multifunction $\mathrm{f}: \mathrm{x} \rightarrow \mathrm{y}$ is called:

(a) Fuzzy lower weakly $\alpha$-continuous at a point $\mathrm{x} \varepsilon \mathrm{X}$ if for every fuzzy open set $\lambda$ in $\mathrm{Y}$ with $\mathrm{x}_{0} \varepsilon \mathrm{F}^{-}(\lambda)$. There exist a $\alpha$-nbd $u$ of $\mathrm{x}_{0}$ in $\mathrm{X}$ such that $\mathrm{UCF}^{-}(\alpha(\operatorname{cl}(\lambda))$. (b) Fuzzy lower weakly $\alpha$-continuous at a point $\mathrm{x} \varepsilon \mathrm{X}$ if for every fuzzy openset $\lambda$ in $\mathrm{Y}$ with $\mathrm{x}_{0} \varepsilon \mathrm{F}^{+}(\lambda)$. There exist a

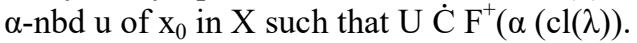

(c) Fuzzy lower weakly $\alpha$-continuous on $X$ if it is respectively so as each $\mathrm{x}_{0} \varepsilon \mathrm{X}$.

(d) Fuzzy weakly $\alpha$-continuous on $\mathrm{X}$ if it is fuzzy lower weakly $\alpha$ - continuous and fuzzy upper weakly continuous.

Theorem (3.1) Let $\mathrm{f}: \mathrm{x} \rightarrow \mathrm{y}$ is fuzzy multifunction, Then following are equivalent:

(a) $\mathrm{F}$ is fuzzy weakly $\alpha$-continuous.

(b) For any fuzzy open set in $\mathrm{Y}_{,} \mathrm{F}^{-}(\lambda) \dot{\mathrm{C}} \alpha$ int $\mathrm{F}^{-}(\alpha \operatorname{cl}(\lambda))$.

Proof: Evident.

Theorem (3.2): Let $\mathrm{f}: \mathrm{x} \rightarrow \mathrm{y}$ is fuzzy lower weakly $\alpha$ continuous if for each fuzzy open set $\lambda, \mathrm{F}^{-}(\operatorname{cl}(\lambda))$ is fuzzy $\alpha$ open set.

Proof: Straight forward.

\section{References}

[1] Ajamal N and Sharma R.D.Fuzzy subcontinuity inverse fuzzy subcontinuity and a new category of fuzzy topological spaces. Fuzzy sets and systems, 73(1995), 13-24.

[2] Chang C.L.Fuzzy topological spaces J.Math.Anal.24(1968),182-190.

[3] Ekici.E.On some types of continuous functions, Appl.Math.E-Not 4(2004), 21-25.

[4] Ewert J. On normal fuzzy topologiical spaces ,Mathematics,31(54)(1989),39-45

[5] Ewert J.Fuzzy valued maps ,Math,Nachr,137(1998),7987.

[6] Mukherjee, M.N. and Malakar,S.,On almost continuous and weakly continuous fuzzy multifunctions,Fuzzy sets and Systems,41(1991),113-125.

[7] Nanda S. On Fuzzy topological spaces, Fuzzy Sets Systems 42(1991),259-262.

[8] Papageorgiou, N.S,Fuzzy topology and fuzzy multifunctions, jour.Math.Anal,Appl, 109(1985),397425.

[9] Thakur S.S.and Malviya R, Pairwise fuzzy irresolute mappings, Math Bohemica 121(3)(1996),273-280.

[10] Zadeh A.Fuzzy sets ,Inform and Control,8(1965),338358. 